\title{
An outbreak of Legionnaires' disease associated with a display spa pool in retail premises, Stoke-on-Trent, United Kingdom, July 2012
}

N Coetzee (nic.coetzee@hpa.org.uk) ${ }^{1}$, H Duggal' ${ }^{1}$, Hawker², S Ibbotson², T G Harrison³ ${ }^{3}$ N Phin ${ }^{4}$, V Laza-Stanca5, R Johnston ${ }^{6}$,

Z Iqbal', Y Rehman'2, E Knapper ${ }^{1}$, S Robinson ${ }^{1}$, N Aigbogun ${ }^{1}$

1. Health Protection Agency, West Midlands North, Stafford, United Kingdom

2. Health Protection Agency West Midlands, Birmingham, United Kingdom

3. Health Protection Agency, Microbiology Services, Reference Microbiology Services, Colindale, United Kingdom

4. Health Protection Agency Health Protection Services, Colindale, United Kingdom

5. University Hospital of North Staffordshire NHS Trust, Stoke-on-Trent, United Kingdom

6. Health Protection Agency, Microbiology Services, Food, Water and Environmental Microbiology Laboratory (Birmingham), Sutton Coldfield, United Kingdom

7. National Health Service Stoke-on-Trent, Stoke-on-Trent, United Kingdom

Citation style for this article:

Coetzee N, Duggal H, Hawker J, Ibbotson S, Harrison TG, Phin N, Laza-Stanca V, Johnston R, Iqbal Z, Rehman Y, Knapper E, Robinson S, Aigbogun N. An outbreak of Legionnaires' disease associated with a display spa pool in retail premises, Stoke-on-Trent, United Kingdom, July 2012 . Euro Surveill. 2012;17(37):pii=20271. Available online: http://www.eurosurveillance.org/ViewArticle. aspx?Articleld=20271

Article submitted on 04 September 2012 / published on 13 September 2012

Twenty-one confirmed cases of Legionnaires' disease (Legionella pneumophila serogroup 1) were identified in the Stoke-on-Trent area of England with onsets since 2 July 2012. Sequence-based typing results are available for nine cases; all are a unique type (ST1268). Initial interviews highlighted a number of possible environmental sources. Inspection of premises of interest revealed an operating spa pool on display, from which the outbreak strain was identified. All cases had visited the retail premise with this spa pool.

On 20 July 2012, public health authorities in the West Midlands, England, were notified of two confirmed cases of Legionnaires' disease (LD) in Stoke-on-Trent residents admitted to the local hospital in the previous week. Initial interviews identified no possible shared exposures, and indicated that neither patient had travelled abroad or in the United Kingdom (UK) during their incubation periods. A review of previous notifications identified two earlier cases resident in this area, one in May and one in June 2012; both had spent part of their incubation periods abroad.

The local Health Protection Unit notified local enforcement agencies and convened an outbreak control team on 23 July 2012 to coordinate investigations, control measures, and public communications, as well as the response by local agencies. This paper describes the preliminary findings of this investigation and summarises data available at 14 August 2012.

\section{Investigation}

The reporting hospital is the only acute care facility serving the residents of Stoke-on-Trent and surrounding districts, a population of approximately 500,000. Active case finding involved close liaison with the microbiology department and medical staff at the hospital, referral of pneumonia cases by hospital clinicians for microbiological testing, and encouraging respiratory sample collection on L. pneumophila urinary antigen-positive patients where possible. Regular letters were sent to all general practitioners (GPS) in the local area asking for vigilance in detecting potential cases, all surrounding hospitals and laboratories were informed to be vigilant and report associated cases, all Health Protection Units across England were briefed, and all national Legionella case reports reviewed.

\section{Case definitions}

A confirmed case was defined in accordance with the definitions from the European Centre for Disease Prevention and Control (ECDC) as a person with clinical or radiological evidence of pneumonia and laboratory confirmation by culture of Legionella pneumophila, by detection of $L$. pneumophila urinary antigen or by seroconversion against L. pneumophila serogroup (sgp)1 [1], and with both an onset date after 30 June 2012 and a history of living in or visiting the Stoke-on-Trent area in the 14 days before onset.

A possible case met the same definition, but with an onset date from 2 May 2012.

\section{Epidemiological investigation}

All detected cases were interviewed with a standard questionnaire within one day of notification, covering details of clinical risk factors, where they lived, worked and visited over the 14 days before becoming ill, including movement routes and visits to or nearby water systems with the potential to be a source of exposure. When cases reported a potential risk site (e.g. a car wash) or any site was mentioned by more than one case, all other cases were re-questioned to determine if they had also visited there. 
Legionnaires' disease cases, by date of onset and case status, Stoke-on-Trent area, May-August $2012(\mathrm{n}=23)$

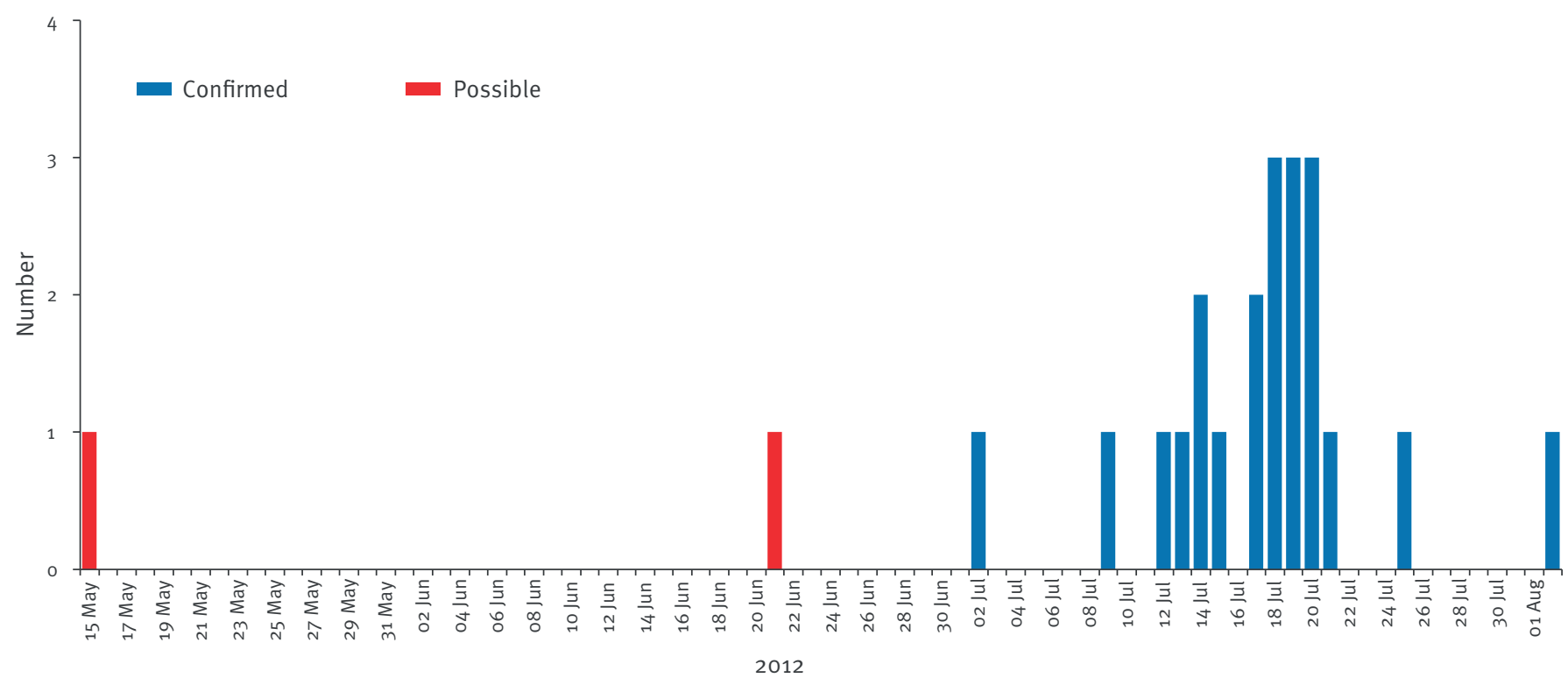

\section{Preliminary results}

As of 14 August 2012, 21 confirmed cases have been identified. Two possible cases with earlier onset have also been re-investigated. All cases live in and around Stoke-on-Trent. The median age of cases is 64 years (range 48-79 years) and 14 of 21 are male. Most cases had existing underlying medical conditions and all were admitted to hospital, where two died. A review of risk factors for disease onset in cases is underway.

All the cases have onset dates from 2 July to 2 August 2012.The epidemic curve (Figure) shows a peak onset (12/21 cases) between 17 and 21)uly, with the majority of those 12 cases occurring from 18 to 20 July (9 cases).

\section{Microbiology of case samples}

All cases were positive for L. pneumophila sgp 1 urinary antigen [2]. Sputum samples were obtained from 11 cases, and direct DNA-sequence based typing (SBT) [3] of the nine L. pneumophila PCR-positive sputum samples identified the same strain (a previously unrecognised sequence type designated ST1268); SBT was not attempted on the two PCR-negative samples. In six cases legionellae have been cultured and the infecting strain confirmed as $L$. pneumophila sgp1, mAb subgroup 'Benidorm', ST1268.

\section{Environmental investigation}

All six active registered cooling towers in Stoke-onTrent were contacted by Health and Safety Executive (HSE) and local authority (LA) inspectors over the weekend 21-22 July to confirm adherence with the nationally approved code of practice for the control of Legionella bacteria in water systems and institute control measures if indicated [4]. Two towers in adjacent districts were included later. Towers were inspected and water samples and swabs of biofilm were taken, although for five of the Stoke-on-Trent towers, this was after initial control measures had been implemented by the owners. All cooling towers were negative by $L$.pneumophila PCR except one of the towers with poor epidemiological fit to the outbreak, which was positive for L. pneumophila sgp1ST62, but not the outbreak strain. This was subsequently confirmed by culture of $L$. pneumophila sgp1, mAb subgroup 'Allentown/France', ST62. All other towers were found to be culture-negative.

Case interviews identified overlapping locations and local travel routes pointing to an area of south Stokeon-Trent for further environmental investigation and assessment of potential water sources. This area was systematically investigated by the HSE and LA, and more than 30 sites (including light industry, engineering works, retail, car washers, dry cleaners, and public fountains) were assessed. Five sites containing water systems with the potential to be a source were inspected and sampled. All samples from these sites were negative in PCR and culture.

Three retail sites common to more than three cases were identified: all 21 cases reported visiting one particular retailer $(A), 20$ of them definitely within the incubation period for the organism, 14 visited another retailer (B) and 10 visited a third (C). Assessment of these three sites found two to have potential sources of exposure: an operating display spa pool (site A) and garden fountains/water features (site B), all of which were drained and disconnected. Samples from site $B$ were negative in PCR and culture. A swab sample (water samples were not available) from the spa pool 
identified the outbreak strain (ST1268) by PCR and direct SBT. Attempts were made to culture L. pneumophila from swab sample concentrates, but have to date not been successful. Maintenance and the use of biocides during the five months the spa pool was operating and on display prior to decommissioning on 24 July are being investigated in detail. On 30 July 2012, seven days after convening the outbreak control team, the media were briefed that the spa pool was the probable source of the outbreak.

\section{Discussion and conclusions}

The epidemic curve and the molecular typing results were highly suggestive of a common source for this outbreak. The use of rapid and detailed investigation techniques confirmed that all cases had visited the indoor retail premises with the display spa pool, and the same, previously unrecognised, strain has been found in all cases tested and in the spa pool. This strain has not been found in any other site tested and no other site had such a strong epidemiological link to all cases. Operating spa pools on display in indoor spaces, even if not used for bathing, have been shown to be the cause of previous outbreaks [5-16]. Although the possibility of ongoing exposure from other sources cannot yet be completely ruled out, the epidemic curve is consistent with the source having been removed on 24 July (the date the spa pool was drained), and no further cases have been identified with disease onset after 2 August.

\section{Acknowledgments}

The authors acknowledge the work of all members of the Outbreak Control Team and the contributions of the following: Caoimhe McKerr, Laura Bayliss, Helen Bagnall, Obaghe Edeghere, Ann Fleming and Chris Bentley, Health Protection Agency (HPA) West Midlands; Rob Carr, Musarrat Afza, Diane Steiner, Sharron Duffin, Linda Morgan, Amie Douglas, Debbie Bowen, Pip Moss, Vicki Fisher, Bernadette Goucher and Neil Bray, West Midlands North Health Protection Unit, HPA; Matthew Bull and Ian Hall, HPA Emergency Response Department; Marilyne Harvey and Deborah Fenelon, HPA Food, Water and Environmental Laboratory (Birmingham); Kathy Nye and Margaret Logan, HPA Public Health Laboratory (Birmingham); Nita Doshi, John Duncan, David Litt, Massimo Mentasti, Dunstan Rajendram, Respiratory and Vaccine Preventable Bacteria Reference Unit, HPA; Matthew Hort, Helen Webster and Laura Burgin, the Met Office; Jeorge Orendi, Krishna Banavathi, Nick Doorbar, Infection Prevention and Control team members, respiratory and critical care, University Hospital of North Staffordshire; Ruth Harrell, West Midlands Public Health Training Scheme; Martyn Brindley, Dawn Birkin and Peter Burgess, Stoke-onTrent City Council; Steve Flanagan, Paul McDermott, David Kivlin, Carl Jones, Janice Dale, Peter Gray, Lyn Mizen, David Brassington, Julie Helps and Priti Shah, Health and Safety Executive; Tracey Malkin, Tracey Shewan, Claire Machin, Neil Adams and Nick Pugh, Staffordshire Cluster of Primary Care Trusts; and NHS Stoke-on-Trent and Staffordshire primary care services and General Practitioners in the affected area.
References

1. Official Journal of the European Union 18.6.2008 L 159/65. COMMISSION DECISION of 28 April 2008 amending Decision $2002 / 253 /$ EC laying down case definitions for reporting communicable diseases to the Community network under Decision No 2119/98/EC of the European Parliament and of the Council (reference number C(2008) 1589) 2008/427/ EC. Available from: http://eur-lex.europa.eu/LexUriServ/ LexUriServ.do?

2. Birtles RJ, Harrison TG, Samuel D, Taylor AG. Evaluation of urinary antigen ELISA for diagnosing Legionella pneumophila serogroup 1 infection. J Clin Pathol. 1990;43(8):685-90

3. Mentasti M, Fry NK, Afshar B, Palepou-Foxley C, Naik FC, Harrison TG. Application of Legionella pneumophila specific quantitative real-time PCR combined with direct amplification and sequence-based typing in the diagnosis and epidemiological investigation of Legionnaires' disease. Eur J Clin Microbiol Infect Dis. 2012;31(8):2017-28.

4. Health and Safety Executive (HSE). Legionnaires' disease. The control of Legionella bacteria in water systems. Approved Code of Practice.and Guidance. London: HSE; 2000. Available from: http://www.hse.gov.uk/pubns/priced/l8.pdf

5. Centers for Disease Control and Prevention. Legionnaires' disease associated with a whirlpool spa display--Virginia, September-October, 1996. MMWR Morb Mortal Wkly Rep. 1997;46(4):83-6.

6. De Schrijver K, van Bouwel E, Mortelmans L, van Rossom P, De Beukelaer T, Vael C, et al. An outbreak of Legionnaire's disease among visitors to a fair in Belgium, 1999. Euro Surveill. 2000;5(11):pii=7. Available from: http://www.eurosurveillance. org/ViewArticle.aspx?Articleld =7

7. Benkel DH, McClure EM, Woolard D, Rullan JV, Miller GB Jr, Jenkins SR, et al. Outbreak of Legionnaires' disease associated with a display whirlpool spa. Int J Epidemiol. 2000;29(6):1092-8.

8. Campese C, Roche D, Clément C, Fierobe F, Jarraud S, de Waelle $P$, et al. Cluster of Legionnaires' disease associated with a public whirlpool spa, France, April - May 2010. Euro Surveill. 2010;15(26): pii=19602. Available from: http://www. eurosurveillance.org/ViewArticle.aspx?Articleld=19602

9. McEvoy M, Batchelor N, Hamilton G, MacDonald A, Faiers $M$, Sills A, et al. A cluster of cases of legionnaires' disease associated with exposure to a spa pool on display. Commun Dis Public Health. 2000;3(1):43-5.

10. Ruscoe Q, Hill S, Blackmore T, McLean M. An outbreak of Legionella pneumophila suspected to be associated with spa pools on display at a retail store in New Zealand. N Z Med J. 2006;119(1243):U2253.

11. Jernigan DB, Hofmann J, Cetron MS, Genese CA, Nuorti JP, Fields BS, et al. Outbreak of Legionnaires' disease among cruise ship passengers exposed to a contaminated whirlpool spa. Lancet. 1996;347(9000):494-9.

12. Redd SC, Lin FY, Fields BS, Biscoe J, Plikaytis BB, Powers P, et al. A rural outbreak of Legionnaires' disease linked to visiting a retail store. Am J Public Health. 1990;80(4):431-4.

13. Den Boer JW, Yzerman EP, Schellekens J, Lettinga KD, Boshuizen HC, Van Steenbergen, et al. A large outbreak of Legionnaires'disease at a flower show, the Netherlands, 1999. Emerg Infect Dis. 2002;8(1):37-43.

14. Kura F, Amemura-Maekawa J, Yagita K, Endo T, Ikeno M, Tsuji H, et al. Outbreak of Legionnaires' disease on a cruise ship linked to spa-bath filter stones contaminated with Legionella pneumophila serogroup 5. Epidemiol Infect. 2006;134(2):385-91.

15. Foster K, Gorton R, Waller J. Outbreak of legionellosis associated with a spa pool, United Kingdom. Euro Surveill. 2006;11(38):pii=3053. Available from: http://www. eurosurveillance.org/ViewArticle.aspx?Articleld=3053

16. Alsibai S, Bilo de Bernardi P, Janin C, Che D, Investigation team, Lee JV. Outbreak of legionellosis suspected to be related to a whirlpool spa display, September 2006, Lorquin, France. Euro Surveill. 2006;11(41):pii=3063. Available from: http:// www.eurosurveillance.org/ViewArticle.aspx?Articleld $=3063$ 
